\title{
PELATIHAN PENGGUNAAN FISHFINDER BAGI NELAYAN KEDONGANAN GUNA MENINGKATAN PRODUKSI PERIKANAN
}

\author{
Y. Suteja ${ }^{1}$, I.G.N.P. Dirgayusa ${ }^{2}$, Widiastuti ${ }^{3}$, I.D.N.N. Putra ${ }^{4}$
}

\begin{abstract}
ABSTRAK
Selat Bali merupakan salah satu wilayah tempat terjadinya kenaikan massa air (upwelling) yang dapat meningkatkan sumber daya ikan. Hal ini membuat Selat Bali umunya dipergunakan sebagai zona penangkapan ikan. Hasil tangkapan ikan di Selat Bali umumnya bersifat fluktuatif tiap musim, salah satu penyebabnya adalah lokasi penangkapan ikan yang tidak tepat. Salah satu alat bantu yang dapat dipergunakan oleh nelayan guna menentukan lokasi penangkapan adalah fishfinder. Fishfinder ini mampu memberikan informasi yang cukup detail yaitu tentang kelimpahan, sebaran, ukuran dan posisi kedalaman renang ikan. Tujuan dari pengabdian ini adalah memberikan pengetahuan dan cara pengoprasian (pemasangan, penggunaan dan pembacaan data) fishfinder bagi nelayan kedonganan. Khalayak sasaran dalam pengabdaian ini adalah nelayan, kelompok nelayan dan pemiliki kapal kelurahan kedonganan. Metode yang digunakan adalah ceramah, praktek penggunaan fishfinder dan diskusi. Kegiatan Program udayana mengabdi yang mengangkat tema pelatihan penggunaan fishfinder bagi masyarakat nelayan berlangsung sangat baik dan memberikan informasi tambahan tentang sejarah, prinsip kerja, kelebihan, kekurangan, jenisjenis, tehnik pemasangan dan praktek cara pengoprasian fishfinder. Hasil pengabdian ini juga menunjukkan adanya atusias yang tinggi oleh masyarakat tentang materi dan praktek yang disajikan yang ditunjukkan oleh adanya interaksi timbal balik saat kegiatan berlangsung.
\end{abstract}

Kata kunci : Pelatihan, Fishfinder, Nelayan, Kedonganan, Praktek

\begin{abstract}
The Bali Strait is one of the upwelling areas that can increase fish resources. This makes the Bali strait generally used as a fishing zone. Fish catches in the Bali Strait are generally fluctuating every season, one of the causes is inappropriate fishing locations. One of the tools that can be used by fishermen to determine fishing location is Fishfinder. Fishfinder is able to provide information about the abundance, distribution, size and swimming depth of fish. The purposes of this service are to provide knowledge and operating techniques (installation, use and reading of data) of fishfinders for fishermen in Kedonganan. The target audiences in this service are fishermen, fishermen groups and ship owners in Kedonganan. The method used in this service is lectures, practice of fishfinder use and discussion. Training of fishfinder use for fishermen is a part of Program Udayana Mengabdi running very well and provide additional information about history, basic principles, strengths, weaknesses, types, installation techniques and practices of how to operate fishfinder.
\end{abstract}

${ }^{I}$ Staf PengajarJurusan Ilmu Kelautan Fakultas Kelautan dan Perikanan Universitas Udayana, yuliantosuteja@unud.ac.id

${ }^{2}$ Staf PengajarJurusan Ilmu Kelautan Fakultas Kelautan dan Perikanan Universitas Udayana, ignpdirgayusa@gmail.com

${ }^{3}$ Staf PengajarJurusan Ilmu Kelautan Fakultas Kelautan dan Perikanan Universitas Udayana, widiastutikarim@unud.ac.id

${ }^{4}$ Staf PengajarJurusan Ilmu Kelautan Fakultas Kelautan dan Perikanan Universitas Udayana,nurweda14@unud.ac.id 
The results of this activity also show that there is a high enthusiasm by the community about the material and practice which is shown by the reciprocal interaction during the activity.

Keywords: Training, Fishfinder, Fisherman, Kedonganan, Aplication

\section{PENDAHULUAN}

Selat Bali merupakan salah satu wilayah perairan di Indonesia yang merupakan tempat terjadinya kenaikan massa air (upwelling) yang bersifat musiman (Hendiarti et al., 2005; Rintaka et al., 2015). Peristiwa upwelling ini membuat kandungan klorofil di Selat Bali meningkat serta meningkatkan sumber daya ikan yang ada (Hendiarti et al., 2005). Hal ini membuat selat bali umunya dipoergunakan sebagai zona penangkapan ikan. Berbagai jenis ikan target tangkapan nelayan Selat Bali adalah ikan lemuru, layang, tongkol, slengseng, Banyar dan Tembang. Walaupaun jenis ikan target beranekaraam, namun jumlah tangkapan ikan di selat Bali umumnya bersifat fluktuatif tiap musim. Data tangkpan ikan yang didaratkan dari selat bali menunjukkan bahwa puncak tangkapan ikan di Selat Bali adalah saat musim peralihan II dan musim barat (Ridha et al., 2013; Simbolon et al., 2011). Hasil yang berbeda didapatkan oleh Prayoga et al. (2017) yang justru mendapatkan hasil tangkapan ikan tongkol paling rendah saat musim barat.

Fluktuasi hasil tangkapan ikan ini umumnya disebabkan oleh factor cuaca, musim, dan lokasi penangkapan ikan yang tidak tepat. Lokasi penangkapan ikan oleh nelayan kedonganan cenderung tidak tepat karena umumnya hanya mengandalakan tanda-tanda alam, perasaan, dan faktor keberuntungan. Bahkan tidak jarang pula saat menurunkan alat tangkap (seperti jaring, pancing, dll), hasil tangkapan tidak maksimal dan jauh dari harapan sehingga pendapatan nelayan menjadi berkurang. Selain itu, kediakpastian lokasi penangkapan membuat nelayan sering berputar-putar tanpa arah sehingga menimbulkan pemborosan bahan bakar minyak dan tenaga. Perilaku ini tentunya membuat proses penangkapan ikan di Selat Bali menjadi tidak efektif dan efisien.

Salah satu alat bantu yang dapat dipergunakan oleh nelayan guna menentukan lokasi penangkapan ikan agar efektif dan efisien adalah fishfinder. Fishfinder adalah teknologi untuk mendeteksi objek bawah air yang bekerja berdasarkan prinsip suara (akustik). Fishfinder ini mampu memberikan informasi yang cukup detail yaitu tentang kelimpahan (kepadatan), sebaran, ukuran dan posisi kedalaman renang ikan. Selain itu kelebihan dari alat ini adalah mampu menjadikan data yang bersifat real time, harga relative terjangkau dan friendly bagi ekosistem. Hasil penelitian yang dilakukan oleh Bhagya dan Prakarsa (2016) menunjukkan bahwa hasil tangkapan ikan dengan aplikasi fishfinder jauh lebih besar dan lebih hemat bahan bakar. Walaupun alat ini memiliki memiliki banyak kelebihan, sayangnya banyak masyarakat nelayan kedonganan yang tidak mengetahui dan memiliki kemampuan untuk mengoperasikannya dengan baik. Pengoprasiannya meliputi pemasangan di kapal, penggunannya dan cara membaca data dari fishfinder. Adanya kombinasi antara teknologi dan kearifan lokal masyarakat nelayan kedongan diharapkan dapat membantu memberikan informasi yang lebih akurat ke nelayan untuk menentukan zona penangkapan ikan sehingga dapat meningkatkan hasil tangkapan dan kesejahtraan nelayan.

Berdasarkan analisis situasi yang dipaparkan diatas tentang kondisi nelayan yang ada di Kedonganan dapat dirumuskan masalah bahwa nelayan belum mendapatkan informasi dan pengetahuan yang cukup tentang fishfinder terutama prinsip kerjanya dan cara memasang, mengoperasikan dan membaca data. Tujuan pengabdian ini adalah memberikan pengetahuan kepada nelayan Kedonganan tentang fishfinder dan prinsip kerja alat serta memberikan pelatihan tentang cara pengoprasian fishfinder termasuk pemasangan, penggunaan dan pembacaan data bagi nelayan Kedonganan. 


\section{METODE PELAKSANAAN}

Pelaksanaan pengabdian pelatihan penggunaan fishfinder mengundang nelayan, kelompok nelayan dan pemilik kapal di wilayah desa Kedonganan dan Tuban. Metode pelaksanaan kegiatan pengabdian ini adalah pemaparan materi tentang fishfinder, praktek penggunaan dan pembacaan fishfinder di laut dan sesi Tanya jawab dalam bentuk diskusi.

\section{HASIL DAN PEMBAHASAN}

Kegiatan Program Udayana Mengabdi yang dilakukan oleh staf pengajar dan mahasiswa ilmu kelautan, Fakultas Kelautan dan Perikanan, Universitas Udayana yang mengangkat kegiatan dengan judul "Pelatihan Penggunaan Fishfinder bagi Nelayan Kedonganan Guna Meningkatan Produksi Perikanan" mengalami perubahan lokasi pelaksanaan. Pada saat perencanaan, kegiatan ini seharusnya dilaksanakan di kelompok nelayan yang ada di Desa Kedonganan, namun karena adanya upacara agama (ngaben masal) maka lokasi pelaksanaan dilaksanakan di Kampung kepiting yang merupakan milik Kelompok Nelayan Wanasari Desa Tuban. Masyarakat yang diundang tetap berasal dari masyarakat Desa Kedonganan dan Desa Tuban. Pada kegiatan pengbadian ini, yang diundang adalah nelayan yang menangkap ikan secara tradisional (pancing atau jaring) dan pihakpihak yang masih terkait dengan kegiatan kelautan perikanan (pemilik kapal, ketua kelompok nelayan, dll).

Pelaksanaan kegiatan program udayana mengabdi ini dilakukan pada hari sabtu 11 Agustus 2018 pada pukul 09.00 - 13.00 WITA. Pada pukul 9.00 WITA dilakukan persiapan kegiatan pengabdian berupa pemasangan layar proyektor, sound system, penyusunan fishfinder, dan pemasangan spanduk kegiatan yang dilakukan oleh team pengabdian dibantu oleh pihak kampung kepiting dan mahasiswa ilmu kelautan. Proses registrasi peserta yang mengikuti pengabdian mulai dilakukan pada pukul $10.00-10.30$ WITA. Kegiatan pengabdian ini diawali oleh sambutan oleh pihak kelompok nelayan wanasari dan di buka secara resmi oleh ketua Unit Penjamin Mutu Fakultas Keluatan dan Perikanan (Gambar 3.1).

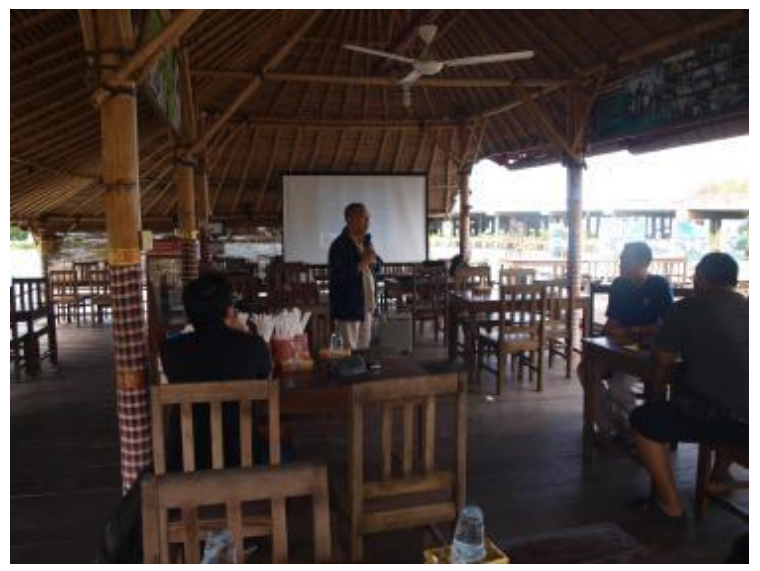

Gambar 3.1. Sambutan sekaligus pembukaan Program Udayana Mengabdi

Proses transfer pengetahuan berupa pemaparan materi Program Udayana Mengabdi (Gambar 3.2) diawali dengan pemaparan sejarah singkat tentang penemuan dan prinsip dasar kerja fishfinder. Selanjutnya dilakukan pemaparan tentang kelebihan dan kekurangan fishfinder. Selain itu diberikan juga pemaparan tentang beberapa jenis fishfinder singlebeam yang umumnya dijual secara umum dipasaran yang memiliki harga yang relative terjangkau dan fishfinder multibeam yang umumnya digunakan untuk kegiatan penelitian. Pemaparan tentang jenis-jenis fishfinder disertakan dengan 
memberikan contoh yang sudah disiapkan dari kampus. Setelah itu dilakukan pemaparan tentang bagian-bagian dari fishfinder dan fungsi dari masing-masing bagian. Pemaparan ini bertujuan agar masyarakat mengetahui bagian-bagian dari fishfinder yang bersifat sensitive sehingga alat dapat digunakan dalam jangka waktu yang lama. Selain itu dijelaskan juga tentang bagian-bagian fishfinder yang tahan air dan tidak tahan air. Selain itu dijelaskan juga tentang jenis-jenis frekuensi suara yang digunakan oleh fishfinder dan perbedaan penggunaan dari tiap-tiap frekuensi yang ada. Bagian terpenting dari pemaparan materi ini adalah tentang cara perangkaian fishfinder dan pemasangan transducer agar peralatan bisa memberikan informasi yang maksimal, tepat dan akurat. Selain itu juga diberikan juga contoh-contoh gambar posisi penempatan transducer di perahu. Proses transfer pengetahuan dasar tentang fishfinder berlangsung sangat lancar dan baik yang dibuktikan dengan keseriusan peserta memperhatikan materi yang disajikan.

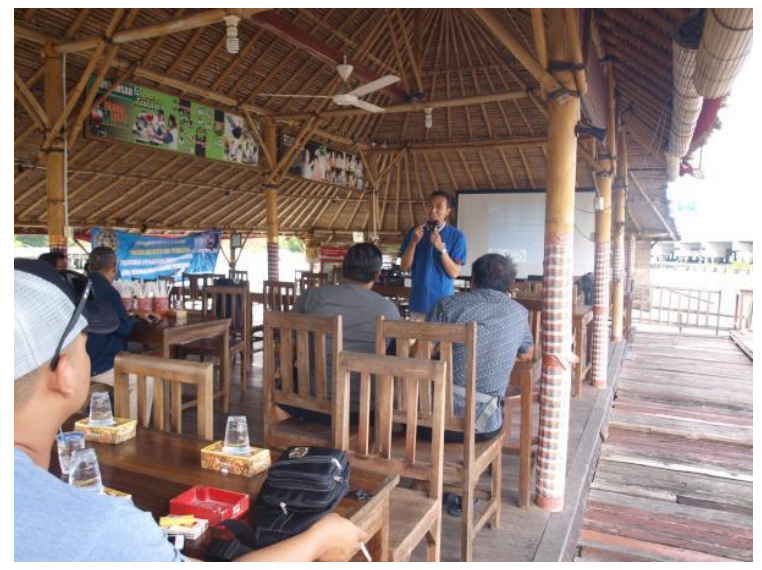

Gambar 3.2. Penyajian materi oleh narasumber

Setelah pemaparan materi, kegiatan selanjutnya dari pengabdian ini adalah praktek langsung tentang perakitan fishfinder dan cara pengoprasian alat sesuai Standar Oprasional Prosedur (SOP) yang dikeluarakan oleh perusahan pembuat fishfinder (Gambar 3.3). Setelah nelayan lancar mengoprasikan fishfinder, bagian terpenting dari praktek ini adalah tentang cara pembacaan informasi yang tersaji pada layar monitor. Masyarakat nelayan sangat antusias mengenai cara pembacaan informasi data yang dibuktikan dengan banyaknya pertanyaan-pertanyaan tekhnis mengenai data yang tersaji di monitor. Proses praktek ini tidak hanya dijelaskan oleh pemateri, namun memberikan kesempatan bagi peserta untuk secara langsung berpartisipasi aktif dalam mengoprasikan alat.

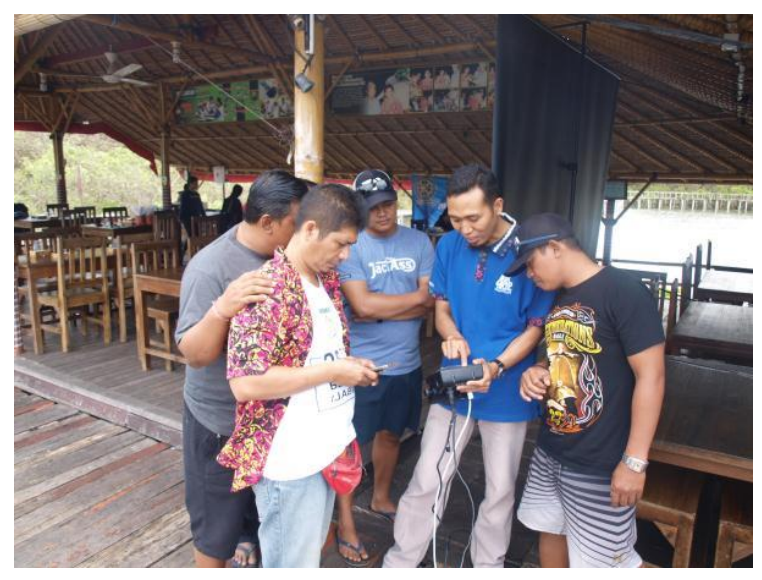

Gambar 3.3. Praktek pengoprasian fishfinder 
Sesi terakhir dari kegiatan pengabdian ini adalah diskusi tentang materi dan praktek yang belum dipahami. Sebagai informasi, bahwa beberapa dari peserta sudah pernah menggunakan fishfinder namun masih banyak yang belum diketahui terutama tentang informasi yang disajikan pada monitor. Beberapa pertanyaan yang diungkatkan oleh peserta pengabdian adalah tentang tingkat akurasi fishfinder untuk menemukan ikan, tehnik perawatan alat yang sesuai dengan SOP, kemampuan untuk mengenal spesies target penangkapan, serta betukar fikiran tentang beberapa kendala tekhnis saat memakai alat. Semua pertanyaan dapat dijelaskan dengan baik oleh pemateri sehingga tidak ada pertanyaan lagi. Sebagai penutup, dilakukan sesi foto bersama antara anggota pengabdian dari ilmu kelautan (staf pengajar dan mahasiswa) dan peserta pengabdian (Gambar 3.4).

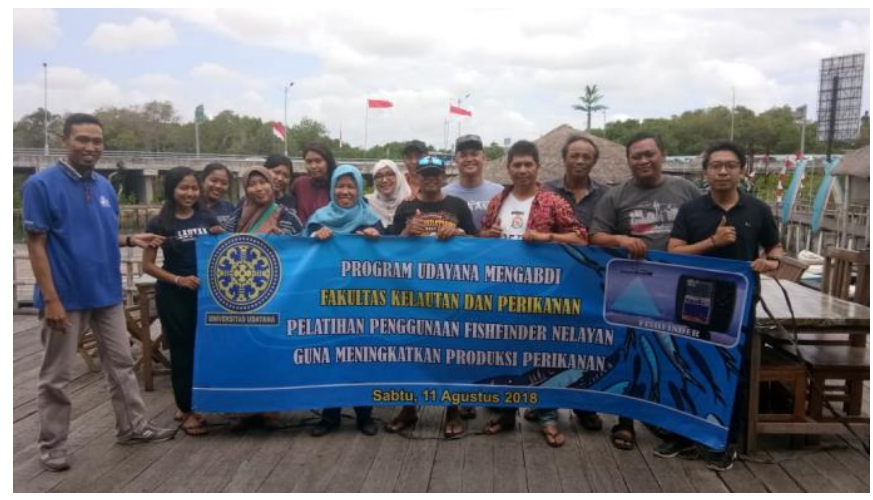

Gambar 3.4. Foto bersama

\section{KESIMPULAN DAN SARAN}

\subsection{Kesimpulan}

Kegiatan Program udayana mengabdi yang mengangkat tema pelatihan penggunaan fishfinder bagi masyarakat nelayan berlangsung sangat baik dan memberikan informasi tambahan tentang sejarah, prinsip kerja, kelebihan, kekurangan, jenis-jenis, tehnik pemasangan dan praktek cara pengoprasian fishfinder. Hasil pengabdian ini juga menunjukkan adanya atusias yang tinggi oleh masyarakat tentang materi dan praketek yang disajika yang ditunjukkan oleh adanya interaksi timbal balik saat kegiatan berlangsung.

\subsection{Saran}

Dari pengabdian yang sudah dilakukan masyarakat nelayan berkeinginan agar diusahakan mendapatkan bantuan fishfinder terutama dari pihak Pemerintah Daerah Kabupaten Badung, Pemerintah Provinsi Bali dan/atau Universitas Udayana agar ilmu yang didapatkan bisa dipraktekkan langsung.

\section{UCAPAN TERIMAKASIH}

Terima kasih kami ucapkan ke Universitas Udayana yang membiaya kegiatan ini melalui Program Udayana Mengabdi tahun 2018. Penulis menyampaiakan penghargaan yang sebesar-besarnya kepada kelompok Nelayan Wanasari di Tuban yang telah memberikan kesermpatan untuk menggunakan fasilitas kelompok nelayan yang ada di Kampung kepiting dan masyarakat Kedonganan, tenaga pengajar di Ilmu Kelautan, mahasiswa dan pihak-pihak yang telah membantu kegiatan pengabdian ini. 


\section{DAFTAR PUSTAKA}

Bhagya, T.G. dan G. Prakarsa (2016). Studi Kelayakan Penerapan Teknologi GPS dan Fish Finder Untuk Meningkatkan Hasil Tangkapan Ikan. In Search Vol 15, pp. 55-60.

Hendiarti, N., E. Suwarso, Aldrian, K. Amri, R. Andiastuti, S. Sachoemar, and I.B. wahyono (2005). Seasonal Variation of Pelagis Fish Catch Around Java. Oceanography. Vol. 18: 4, pp. 112-123.

Prayoga, I.M.S., I.D.N.N. Putra, dan I.G.N.P. Dirgayusa (2017) Pengaruh Sebaran Konsentrasi Klorofil-a Berdasarkan Citra Satelit terhadap Hasil Tangkapan Ikan Tongkol (Euthynnus sp) Di Perairan Selat Bali. Journal of Marine and Aquatic Sciences. Vol 3: 1, pp. 30-46.

Ridha, U., M.R. Muskanofala, dan A. Hartoko (2013). Analisa Sebaran Tangkapan Ikan Lemuru (Sardinella lemuru) Berdasarkan Data Satelit Suhu Permukaan Laut dan Klorofil-a di Perairan Selat Bali. Diponegoro Journal of Maquares. Vol 2: 4, pp. 53-60.

Rintaka, W.E., E. Susilo, dan A.W. Hastuti (2015). Pengaruh In-Direct Upwelling Terhadap Jumlah Tangkapan Lemuru Di Perairan Selat Bali. Seminar Nasional Perikanan dan Kelautan V Universitas Brawijaya. pp. 312-319.

Simbolon, D., B. Wiryawan, P.I. Wahyuningrum, dan H. Wahyudi (2011). Tingkat Pemanfaatan dan Pola Musim Penangkapan Ikan Lemuru di Perairan Selat Bali. Buletin PSP. Vol 19: 3, pp. 293-307. 